\title{
Patterns of Root Production and Mortality during Transplant Establishment of Landscape-sized Sugar Maple
}

\author{
Lisa E. Richardson-Calfee and J. Roger Harris ${ }^{1}$ \\ Department of Horticulture, Virginia Polytechnic Institute and State University, 301 Saunders Hall, \\ Blacksburg, VA 24061 \\ Robert H. Jones \\ Department of Biological Sciences, Virginia Polytechnic Institute and State University, 2125 Derring \\ Hall, Blacksburg, VA 24061
}

\author{
Jody K. Fanelli ${ }^{1}$ \\ Department of Horticulture, Virginia Polytechnic Institute and State University, 301 Saunders Hall, \\ Blacksburg, VA 24061
}

\begin{abstract}
AdDitional INDEX wORDs. balled-and-burlapped, pot-in-pot, rhizotron, season, standing crop, turnover
Abstract. Root system regeneration after transplanting of large trees is key to successful establishment, yet the influences of different production systems and transplant timing on root growth remain poorly understood. Patterns of new root production and mortality were therefore measured for 1 year after transplanting landscape-sized Acer saccharum Marsh. (sugar maple). Trees were transplanted into root observation chambers (rhizotrons) from two production systems, balled-and-burlapped (B\&B) and pot-in-pot (PIP), in November, December, March, April, and July and compared with non-transplanted trees. Although root production stopped in midwinter in all transplants and non-transplanted field-grown trees, slight wintertime root production was observed in non-transplanted PIP trees. Root mortality occurred year-round in all treatments with highest mortality in winter in the transplanted trees and spring and summer in the non-transplanted trees. Non-transplanted PIP trees had significantly greater standing root length, annual production, and mortality than non-transplanted field and transplanted PIP trees. For B\&B trees, greatest standing length, production, and mortality occurred in the April transplant treatment. Production and mortality were roughly equal for non-transplanted trees, but production dominated early dynamics of transplanted trees. Overall, increases in root length occurred in all treatments, but the magnitude and timing of root activity were influenced by both production system and timing of transplant.
\end{abstract}

Root systems of most nursery-grown landscape trees extend well beyond the edge of the canopy. As a result, when large (greater than $2 \mathrm{~m}$ tall) field-grown trees are harvested for transplanting, only a small portion of the root system is moved and a high percentage of fine, absorbing roots are lost (Gilman, 1988; Gilman and Beeson, 1996a). As a consequence, newly transplanted field-grown trees must be supported by a small fraction of the original absorptive root surfaces. Tissue water deficit resulting from an inability to absorb sufficient soil moisture to support the tree is thought to be the primary cause of transplant stress (Larson, 1984), and the rate of recovery from post-transplant water stress is directly proportional to the rate of regeneration of new roots (Nambiar et al., 1979). Thus, the more quickly a tree can regenerate a root system, the sooner the tree will establish. In contrast to the significant loss of roots that occurs when trees are dug from the field, all roots of container plants are within the confines of the container; thus, little root weight or length will be lost during transplant unless

Received for publication 9 Dec. 2009. Accepted for publication 12 Apr. 2010. We gratefully acknowledge Dan Ward and Michelle Marini for their assistance with statistical analysis and Allen Safrit for his help transplanting trees. In addition, we would like to acknowledge Marcus Jones, Lisa Kelk, Sherry Musslewhite, Mary Stanley, Joel Shuman, Donnie Sowers, and Matt Thacker for their assistance.

${ }^{1}$ Corresponding author. E-mail: rharris@vt.edu. root balls are altered. As a result, container-grown trees may be less likely to suffer moisture stress when transplanted if adequately irrigated (Gilman and Beeson, 1996b).

For all transplanted trees, the production and maintenance of new roots is costly. Root turnover, an indicator for the cost of root production, refers to the portion of the root system that dies and is replaced (Burton et al., 2000) and is a measure of annual production and/or mortality relative to standing crop (Jones et al., 2003). In natural forests, root turnover is responsible for a substantial flux of carbon to the rhizosphere (Tierney and Fahey, 2002) and is, therefore, a substantial metabolic cost for trees (Psarras et al., 2000). In a sugar maple-dominated forest, $40 \%$ to $60 \%$ of the net primary productivity was allocated to fine root production, and annual root biomass production and mortality were estimated to be 7300 to $8000 \mathrm{~kg} \cdot \mathrm{ha}^{-1}$ per year and 4800 to $6700 \mathrm{~kg} \cdot \mathrm{ha}^{-1}$ per year, respectively (Hendrick and Pregitzer, 1993b).

Bloomfield et al. (1996) proposed three categories of processes that affect the magnitude and timing of root turnover. Processes in the first category are a result of aboveground demands that affect carbon fixation (e.g., foliage production, thinning of branches, and prolific fruiting) and carbon allocation. The second category relates to carbohydrate storage capacity and assumes that roots die when there is insufficient carbon for maintenance. Larger roots usually have larger carbon reserves and thus often live longer. The third category 
of processes encompasses factors that affect soil microsite quality (e.g., nutrient, water, and oxygen availability, soil temperature, toxic elements, and fungal/microbial populations).

Plasticity in the response of root turnover rates to changes in soil environment may be considered a fitness attribute because plants that respond to changing conditions can better compete for resources in a heterogeneous environment (Espeleta and Donovan, 2002; Hutchings, 1988). As such, trees exhibit a morphological plasticity that results in proliferation of roots in favorable environments and shedding of roots after a region of soil has been depleted of resources (Pregitzer et al., 1993). For example, addition of nitrogen to a mixed hardwood forest resulted in a rapid increase in localized fine root production (Hendrick and Pregitzer, 1992, 1993a), increased longevity, and reduced turnover rates (Burton et al., 2000). Burton et al. (2000) suggested that roots are maintained as long as the benefit they provide outweighs the carbon cost of keeping them alive.

The rapid regeneration of a new root system is essential for the survival of a newly transplanted tree. Thus, basic information concerning the dynamics of how root systems develop after transplanting will improve our understanding of how trees establish and survive. The work described in this article is an exploration of aspects of root turnover in a horticulture system as opposed to a forest ecology system. In what may be the only other report on production and mortality in regenerating roots systems of transplanted landscape trees, Wiseman and Wells (2009) monitored balled-and-burlapped (B\&B) Magnolia virginiana L. (sweetbay magnolia) and Acer buergerianum Miq. (trident maple) for 1 year after transplanting with minirhizotrons. However, their study did not address this phenomenon when comparing production methods or transplant dates. The objectives of this research were therefore to characterize the patterns of root production and mortality (turnover) of newly expanding root systems of recently transplanted sugar maples and to determine the effects of transplant timing and production system [B\&B or pot-in-pot (PIP)] on these processes. The B\&B system was predicted to have greater overall root activity as a result of the loss and subsequent replacement of fine roots when B\&B plants are harvested for transplanting. The timing of transplanting was predicted to have a major influence on both root production and mortality reflecting physiological links between above- and belowground growth.

\section{Materials and Methods}

Plant material. Bare root, sparsely branched sugar maples $(\approx 1.2 \mathrm{~m}$ tall) were obtained from J. Frank Schmidt and Sons Co. (Boring, OR) and grown in a nursery bed or PIP production system for 2 years at the Urban Horticulture Center, Blacksburg, VA. Trees in the nursery bed were spaced $1.4 \mathrm{~m}$ apart in a row. Soil type in the nursery bed was a Groseclose silt loam (clayey, mixed, mesic Typic Hapludults) with pH 6.2. The PIP production system consisted of 51-L black, plastic containers (B-15; Nursery Supplies, Mobile, AL) fitted into 51-L black, plastic socket (belowground) containers spaced $1.2 \mathrm{~m}$ on center in rows $1.5 \mathrm{~m}$ apart. Black landscape fabric covered the area between the sockets, and an underground drainage system ensured that containers were never in standing water. Container substrate consisted of unamended milled pine bark ( $\mathrm{pH}$ 6.2). In Sept. 2000, 24 uniform-sized, field-grown, and PIP trees were selected. Height for field-grown and PIP trees [mean (SE)] were $2.62(0.07) \mathrm{m}$ and $2.84(0.08) \mathrm{m}$, respectively. Trunk diameters
$15 \mathrm{~cm}$ above the soil line were $69.8(3.0) \mathrm{mm}$ and $72.0(1.8) \mathrm{mm}$ for field-grown and PIP trees, respectively.

Treatments. Treatments consisted of two production methods (B\&B and PIP) and five transplant dates that represent distinct seasonal or phenological events [3 Nov. 2000 (leaf drop), 8 Dec. 2000 (late fall), 16 Mar. 2001 (early spring), 13 Apr. 2001 (bud break), and 13 July 2001 (bud set)]. The July transplant date was selected as the date when twig extension had stopped on at least four of five preselected twigs on nontransplanted trees. Rhizotrons for the non-transplanted trees were located in the PIP system and nursery bed and could not be randomized in the same bed as the transplanted trees. Consequently, the experimental design consisted of a two production system $\times$ five transplant date factorial arranged in a completely randomized design and augmented with two non-transplanted controls (field and PIP trees). There were four replications of each treatment.

RHizotrons. Three types of rhizotrons were constructed. A field rhizotron (FR) was constructed around the nontransplanted field trees by excavating a ditch and framing a polycarbonate viewing panel in front of individual trees. Pot-in-pot rhizotrons (PIPR) were constructed for the nontransplanted PIP trees by fashioning a polycarbonate window in individual 51-L plastic nursery containers. Insulated aboveground rhizotrons (AGR) were constructed by fitting a polycarbonate window in individual pyramidal-shaped plastic supports manufactured to prevent 51-L nursery containers from wind throw for all transplanted trees in nursery beds adjacent to the PIP system and the non-transplanted trees. See RichardsonCalfee et al. (2007) for more detailed rhizotron descriptions. The 2007 report described the timing and magnitude (i.e., periodicity) of first-season root, shoot, and trunk growth of sugar maples after transplanting and it used the same rhizotrons as the current study. In the 2007 report, root growth and mortality were not measured separately and root growth reflected the cumulative changes in length density of live roots (i.e., standing crop).

Tree harvest and Planting. Before transplanting into rhizotrons, field-grown trees were harvested $\mathrm{B} \& \mathrm{~B}$ by hand digging with 51-cm-diameter root balls, wrapping root balls with industry-standard copper sulfate-treated burlap (A.M. Leonard, Piqua, $\mathrm{OH}$ ), and tightly lacing them with sisal twine. Circling roots on PIP trees were pruned to prevent further circling and to encourage root exploration into the surrounding soil and substrate. A dense layer ( $\approx 1 \mathrm{~cm}$ thick) of roots on the bottoms of the root balls of all PIP trees was also removed. Rhizotrons were carefully lowered over the tree tops, making sure not to damage the buds and twigs. Root balls were positioned close to $(\approx 2 \mathrm{~cm})$ and centered in front of the windows. After positioning the trees in the rhizotrons, a 1:1 (vol:vol) mixture of sphagnum peat and coarse sand was used to fill the space between the root balls and AGR windows. Burlap and twine were loosened from around the tree trunks but left intact around the root ball of field-grown trees. All transplanted trees were flood-irrigated after transplanting, and spaces that opened up between the root ball and windows were filled with additional peat and sand mixture. All transplanted trees were mulched with $\approx 7 \mathrm{~cm}$ of mixed hardwood bark. Unamended pine bark $(\mathrm{pH}$ 6.3) was used to fill the small gap present between the root balls of the non-transplanted trees and the rhizotron windows when the PIPR were constructed. Except for installation of the rhizotron, no modifications were made to the four non-transplanted control trees that were left in the field. 
The same peat and sand mixture used to fill the space between the root balls and AGR windows was used to fill the space between the soil profile and FR windows.

Tree CaRe. Trees were fertilized with $200 \mathrm{~g}$ of $15 \mathrm{~N}-3.9 \mathrm{P}$ $10 \mathrm{~K}$ encapsulated slow-release fertilizer (Osmocote Plus 159-12, 8-9 Month Northern Formula; Scotts, Marysville, OH) just before spring bud break each year. All trees were irrigated with a microirrigation system in such a manner as to maintain soil and substrate moisture near field/container capacity. During the first growing season (2001), trees in the AGR and FR were irrigated twice weekly, and during 2002, trees were irrigated about once per week. Trees in the PIPR were irrigated daily during both growing seasons unless it rained. Irrigation occurred less often when sufficient rainfall was received or after leaf drop. As a result of strong wind, two trees from the July transplant treatment had to be staked after transplanting. Survival was $100 \%$ for all B\&B trees. However, three PIP trees died over the course of the project, two (one PIP/March and one PIP/April) of unknown causes and one (PIP/March) that snapped at the base of the trunk during a wind storm.

Measurements ANd anAlysis. A $25 \times 25-\mathrm{cm}$ grid with lines in $5-\mathrm{cm}$ increments was drawn on the observation panels (all on the north side) of all rhizotrons. Two individual $5 \times 5-\mathrm{cm}$ grid boxes, 12 to $17 \mathrm{~cm}$ below the soil surface sections, were selected on each rhizotron for turnover analysis. The grid boxes selected were $15 \mathrm{~cm}$ apart from the inside edges and centered under tree trunks. Data from the two grid boxes were pooled for each tree. Photographs were taken weekly with a digital camera at $1600 \times 1200$ pixels to document changes in root length against the rhizotron window for $\approx 1$ year. Measurements began 28 June 2001 until root production stopped in winter. During winter, rhizotron windows were photographed monthly until early spring, at which time weekly measurements resumed. Root systems of all transplanted trees were excavated on 10 June 2002 to evaluate the total dry mass of new roots regenerated for the treatments described in the current study (Richardson-Calfee et al., 2008). Consequently, the photographic documentation of the transplanted tree's root systems stopped on 5 June 2002. Non-transplanted trees were not excavated and so their root activity was followed until 24 July 2002. Image color, contrast, and brightness of all images were adjusted in Adobe Photoshop (Version 6.0.1; Adobe Systems, San Jose, CA) to facilitate visual analysis.

All roots intersecting these two $5 \times 5-\mathrm{cm}$ measurement frames (i.e., grid sections) were counted on each measurement date. Intersections observed for the first time were considered new roots. Individual root/line intersections were tracked over time to determine the date of death of each individual root, and roots were considered dead on the first date that they disappeared entirely and permanently from subsequent images or appeared to be dead as a result of change in color (to gray or black) (Jones et al., 2003). Standing root length (total root length at a given moment in time), new live root length, and new dead root length were calculated from the counts of root/ line intersections (Marsh, 1971; Newman, 1966; Tennant, 1975). Root/line intersections were converted to lengths using: $\mathrm{R}=(11 / 14)(\mathrm{N})$ (grid unit) in which $\mathrm{N}=$ total root/line intersections and grid unit $=5 \mathrm{~cm}$. Soil and substrate temperatures were monitored with thermocouples placed $30 \mathrm{~cm}$ deep and $\approx 1 \mathrm{~cm}$ from observation windows in the AGR, PIPR, FR, and nursery ground bed. Afternoon soil temperatures were recorded twice weekly for the duration of the project.
Mean standing root length (synonymous with standing crop) was calculated as the mean of the largest four measurements from the first growing season. Total new root length or annual production of the transplanted trees was the sum of all new root lengths during the first year after transplant beginning at the onset of observable root system regeneration on 2 May 2001 and ending 1 year later on 5 May 2002. Total dead root length or annual mortality of the transplanted trees was the sum of all dead root lengths during the same period.

Trees in early stages of establishment do not reach a steady state that can be used to estimate long-term turnover. Therefore, we chose to assess four popular indices of root activity that reveal different relationships: 1) a measure of relative production and mortality (RPM), calculated as the sum of total new and dead root lengths divided by mean standing root length $[(\mathrm{N}+\mathrm{D}) / \mathrm{SC}$ in which $\mathrm{N}=$ total new root length or annual production, $\mathrm{D}=$ total root length that permanently disappeared or annual mortality, and $\mathrm{SC}=$ mean standing root length or standing crop (Hendrick and Pregitzer, 1992; Jones et al., 2003)]; 2) a measure of relative production (RP), calculated as total new root length divided by mean standing root length [N/SC (Burton et al., 2000; Hendrick and Pregitzer, 1993a)]; and 3) a measure of relative mortality (RM), calculated as total dead root length divided by mean standing root length [D/SC (Burton et al., 2000)]. By using the mean standing root length as the denominator, effects of root system size in the vicinity of the rhizotrons can be factored out in the comparisons of treatment impacts on growth and mortality. Finally, 4) the ratio of production to mortality (P:M) was also calculated as the sum of total new root lengths divided by total dead root length [N/D (Burton et al., 2000)].

Standing root length, new root length (root production), dead root length (root mortality), and soil temperature were plotted over time to illustrate seasonal patterns of standing root length and root production and mortality. Mean standing root length data, annual production and mortality data, and the indices of activity were subjected to analyses of variance to determine significance of treatments in the MIXED procedure of SAS (Version 8.02; SAS Institute, Cary, NC) using repeatedmeasures analysis of variance. Statistical comparisons within treatments were made using a priori single degree of freedom (df) linear contrasts with a significance level set at $P=0.05$. Individual B\&B treatments were compared with individual PIP treatments with a priori single df linear contrasts and actual probability values are presented.

\section{Results and Discussion}

Seasonal PATterns OF ROOT PRODUCTION. Seasonal trends of root production generally agree with periodic patterns of change in standing crop over time expressed as percent change per day that we reported previously (Richardson-Calfee et al., 2007). However, in the current study, we focus on individual roots in specific sections of the rhizotrons so that production and mortality can be separated. In these closely monitored sections, we found that regardless of the transplant treatment (November, December, March, and April), no root growth was observed until after 2 May 2001. Less than half of the trees had observable root growth by 9 May 2001, and slightly over half had observable root growth by 17 May 2001.

Periods of abundant root production were restricted to the warmer months of the year for all trees (Figs. 1 and 2). First 


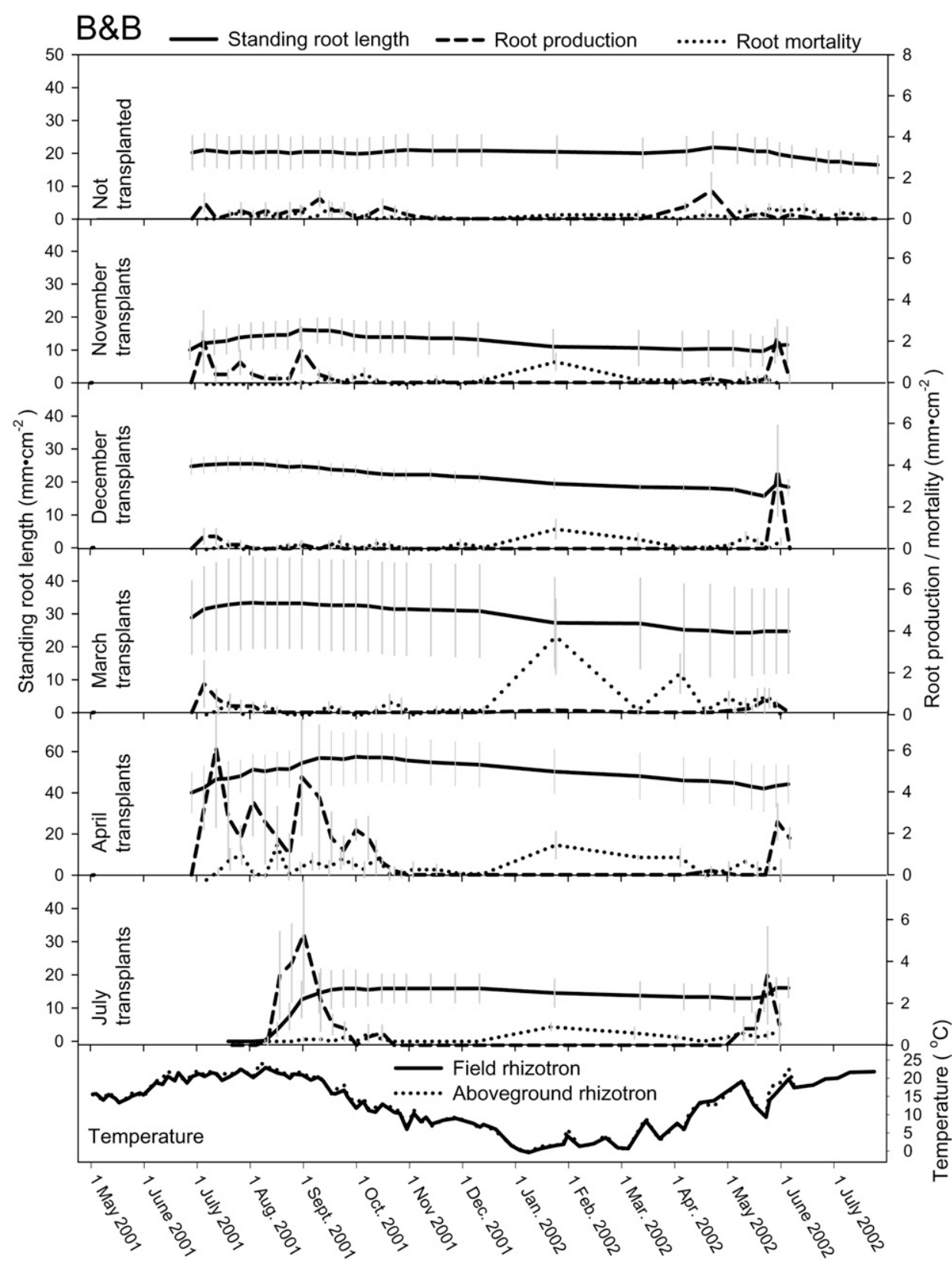

Fig. 1. Seasonal pattern of standing root length, root production, and root mortality of balled-and-burlapped (B\&B) sugar maple transplanted in Nov. and Dec. 2000 and Mar., Apr., and July 2001. Scale for standing root length on the left $\mathrm{y}$-axis is a different scale than root production/mortality (on right $\mathrm{y}$-axis); bars $=\mathrm{SE}(\mathrm{n}=4)$.

Root production in the nontransplanted PIP trees continued throughout the year (Fig. 2), although production was minimal between late October and early May. Burton et al. (2000), Harris and Fanelli (1999), and Morrow (1950) also reported minimal root growth throughout winter. The resumption of substantial early spring root production in non-transplanted field trees and the occurrence of root production in non-transplanted PIP trees throughout winter indicate that early spring soil temperatures were not limiting to early spring root production. The lack of early spring root production before bud break in the transplanted trees likely relates to the adverse effects of transplanting on tree physiology (i.e., transplant stress) and the limited supply of non-structural carbohydrates necessary to support root growth before bud break. Several authors suggest that during shoot expansion, shoots act as a stronger sink than roots (Bevington and Castle, 1985; Deans and Ford, 1986). A decline in carbohydrate reserves during periods of shoot growth and a corresponding reduction in root growth have been reported in several species (Lathrop and Mecklenburg, 1971; Merritt, 1968). The occurrence of winter root production in non-transplanted PIP trees may be a temperaturedriven response because late fall, winter, and early spring temperatures in the PIPR were slightly [ 1 to $3{ }^{\circ} \mathrm{C}$ (Fig. 3)] warmer than the AGR or FR. Cool-season temperatures in the AGR and FR were nearly identical (usually within $1{ }^{\circ} \mathrm{C}$ ). In addition, root growth in the PIPR was restricted to the pot and, as a result production activity in the PIPR, would more likely be detected. The

season (2001) root production stopped at the time of leaf drop in the fall (mid-October), when soil temperatures were near 12 to $14{ }^{\circ} \mathrm{C}$ (Fig. 3), and resumed in the transplanted trees the next May, $\approx 1$ month after bud break (18 May 2002), when soil temperatures rose above $10{ }^{\circ} \mathrm{C}$. Root production in the nontransplanted field trees stopped at a similar time as in the transplanted trees; however, production resumed in mid-March ( $\approx 2$ months before the transplanted treatments) when soil temperatures were near 4 to $8{ }^{\circ} \mathrm{C}$ and before bud break. Similarly, other authors (Burton et al., 2000; Harris and Fanelli, 1999; Morrow, 1950; Taylor and Dumbroff, 1975) reported substantial root growth of sugar maple before bud break in spring (Michigan, southwest Virginia, central New York, and Ontario, respectively).
AGRs are open-bottomed and the FR is open on all sides but one. Therefore, root production may have been occurring in areas outside the view of the rhizotron windows. Root systems of trees transplanted in the AGRs and trees in the FR also may have reached a density such that conditions were no longer favorable for production in the localized area near the rhizotron windows. Other authors report reductions in root growth as a result of competition, unfavorable densities, and resourcecontrolled carrying capacity for roots (Jones et al., 2003; Vogt et al., 1981; Watson, 1987; Watson and Sydnor, 1987).

Compared with other transplant treatments, the July transplants exhibited a relatively large burst of root production activity late in summer (Figs. 1 and 2). This anomalous root production was likely a result of stimulation by root pruning 


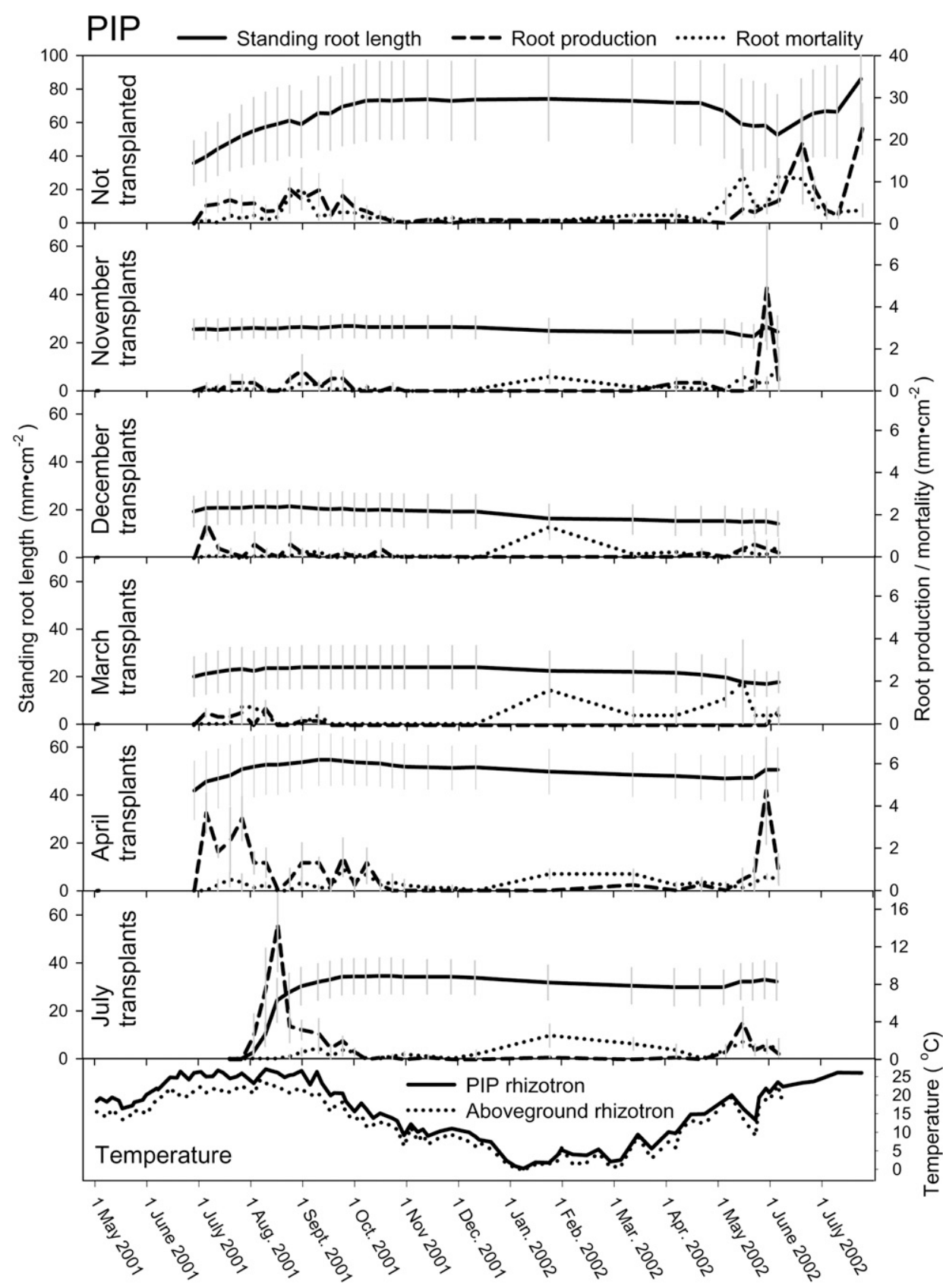

Fig. 2. Seasonal pattern of standing root length, root production, and root mortality of pot-in-pot (PIP) sugar maple transplanted in Nov. and Dec. 2000 and Mar., Apr., and July 2001. Scale for standing root length on the left $\mathrm{y}$-axis is a different scale than root production/mortality (on right y-axis). Scales for non-transplanted trees differ from other treatments; bars $=\mathrm{SE}(\mathrm{n}=4)$. (e.g., transplanting) when soil temperatures were not limiting (Cripps, 1970; Wang et al., 1995). Species more prone to desiccation may not be able to take advantage of the favorable soil temperatures when transplanted in summer.

SEASONAL PATTERNS OF ROOT MORTALITY. Although root production was restricted from early fall until late spring, root mortality occurred throughout the year and at a much steadier rate. Similarly, Burton et al. (2000) reported that sugar maple root mortality in a forest environment was more uniformly distributed throughout the year than was root production.

Although all of the transplanted treatments exhibited maximum root mortality in winter, the nontransplanted treatments did not (Figs. 1 and 2). The period of maximum root mortality of the non-transplanted PIP trees occurred in spring just before the period of maximum root production in May and June (at the time of bud break and shoot expansion) (Fig. 2). Maximum root mortality in the non-transplanted field trees began at a similar time as the nontransplanted PIP trees but continued until the trees were excavated. Burton et al. (2000) found that root mortality in sugar maple in a forest environment was highest between May and August and occurred at a similar time as maximum root production (sometimes just before and other times just after). The physiological expense of maintenance respiration (Amthor, 1984) of the roots and competition for assimilates between the roots and shoots during periods of growth may be partly responsible for increased rates of root mortality just before spring bud break.

Similar to the low rates of wintertime root mortality observed in the non-transplanted trees in this study, Hendrick and Pregitzer (1993b) observed low winter mortality relative to the growing season in a sugar maple-dominated forest. Root respiration costs can be high for plants, and although maintenance respiration occurs year-round, respiration is greatly influenced by temperature. Respiration rates typically increase exponentially with increasing temperature, but only over a certain range (usually between 10 and $25^{\circ} \mathrm{C}$ ) (Eissenstat and Yanai, 1997; Kozlowski and Pallardy, 1997; Lawrence and Oechel, 1983). Thus, low wintertime root mortality rates in the non-transplanted trees in this study relative to late spring and early summer rates may reflect low respiration rates in cold soils (Hendrick and Pregitzer, 1993b).
Fig. 3. Soil temperature at $30 \mathrm{~cm}$ depth taken in the field rhizotron (FR), pot-inpot rhizotron (PIPR), aboveground rhizotron (AGR), and nursery bed. 
Increased root mortality in May and June in this study may also relate to the greater carbon demand of the developing canopy and a corresponding reduction of carbohydrate translocation or carbon allocation to the roots during shoot growth. Stored carbon in roots is essential to growth of roots and leaves early in the growing season (Eissenstat and Yanai, 1997). Therefore, root carbon stores may be mobilized to supply carbon to the young roots and shoots. During the growing season, when trees are actively photosynthesizing, root growth is primarily supported by current-season photosynthates (Marshall and Waring, 1985). Hobbie et al. (2002) reported that $75 \%$ of fine root carbon originated from current-year photosynthate and Dickson (1991) reported that after a flush of shoot growth, more than $90 \%$ of photosynthate was translocated to the roots.

Two models have been proposed to explain root longevity and mortality patterns (Bloomfield et al., 1996). In the first model, roots have an indeterminate lifespan and only die when environmental factors are no longer favorable, thereby lowering the maintenance costs for the plant when they cannot be effectively used. In the second model, roots have a predetermined lifespan dependent on a finite supply of starch/carbon that, when exhausted, results in root death (Marshall and Waring, 1985). Because the lack of leaves limits photosynthesis during winter months for deciduous temperate zone trees, wintertime root mortality in the transplanted trees may be driven by the reallocation of non-structural carbohydrates/ resources for winter maintenance respiration. Alternatively, the abundant wintertime root mortality observed in transplanted trees may represent an inherently shorter lifespan of the first roots regenerated after a tree is transplanted. Watson and Himelick $(1982,1983)$ reported that, although numerous roots are produced from each severed root end, in most cases, one (or at most, a few) roots will become dominant within a couple of years and the remainder of the small roots will die (Watson, 1986). Therefore, the first roots regenerated after a tree is transplanted may serve as "temporary" roots that grow quickly and support the newly transplanted tree until a more permanent root system is regenerated. The rapid production of roots on newly transplanted trees serves to prevent desiccation by quickly increasing the absorptive capacity of the root system. Maintaining this capacity yet simultaneously increasing the foraging area by growing long roots would carry a hefty metabolic cost. Shedding excess roots near the root ball so that resources can be spent on longer foraging roots fits the economic model in which resources are spent where needed and withdrawn when not (Bloom et al., 1985).

Seasonal Patterns of Standing root Length. Mean standing root length is a combination of root production and mortality. Although most of the transplanted treatments underwent a slight decline in standing root length between late summer and the next spring, standing root length of the nontransplanted field treatment remained relatively stable over winter and underwent a slight decline in spring (Fig. 1). Hendrick and Pregitzer (1993a) reported slight declines in standing root length in winter and spring in a sugar mapledominated forest. Similar to the non-transplanted field trees, non-transplanted PIP trees did not undergo substantial root mortality during winter months (Fig. 2). However, substantial root mortality occurred in non-transplanted PIP trees just before the periods of rapid root production in early May. As such, the standing root length of the non-transplanted PIP trees remained relatively stable over winter, declined in late April and May, and then increased in June and July. Several authors (Hendrick and Pregitzer, 1993a; Kolesnikov, 1971; Santantonio and Grace, 1987) also report a relationship between root production and mortality and seasonal conditions. During cold months, root production and standing root biomass in a Pinus palustris Mill. (longleaf pine) woodland declined, whereas during warm months, production and biomass increased (Jones et al., 2003). Similarly, Hendrick and Pregitzer (1992) reported peaks of high live biomass in summer and drops in live root biomass in late summer and fall for a sugar maple-dominated forest.

MeAN STANDING ROOT LENGTH AND ANNUAL ROOT PRODUCTION AND MORTALITY. In the overall analysis of variance model, no significant interactions were found between production method and transplant date for standing root length, root production, and root mortality $(P=0.616,0.753$, and 0.512 , respectively). However, when a priori tests were made to compare each method within individual transplant treatments, two patterns emerged that suggest an important interaction did exist between transplanting date and production method. First, non-transplanted PIP trees had greater mean standing root length and annual production and mortality than non-transplanted field trees or transplanted PIP trees (Table 1). As a result of the confinement of root systems of containerized trees, it was expected that the nontransplanted PIP trees would have a greater standing root length than the field trees, whose roots could freely explore the surrounding soil. Second, mean standing length, production, and mortality were greater in April transplants than in other transplant dates, but the differences were significant only for the B\&B production system (Table 1). April transplants may have had greater root production than other treatments as a result of favorable environmental conditions (e.g., ample soil moisture, cool air, warming) and subsequently a reduced potential for desiccation through minimization of transpiration loss at the time of transplant.

The strong effect of production method on non-transplanted trees may be partly a result of the basic difference in root morphology resulting from production in field soil versus production in container systems with organic substrates, in which the container-grown trees have more small diameter roots than comparable trees in field soil and thus more root length and root tips (Harris and Gilman, 1993).

INDICES OF ROOT ACTIVITY AND ROOT PRODUCTION AND MORTALITY RATIOS. The RPM index can be thought of as a measure of total root activity because it is calculated as the sum of total new and dead root lengths divided by the mean standing root length. The RP index can be thought of as a measure of production relative to mean standing root length, whereas the RM index is a measure of relative mortality. The P:M index is a ratio of the sum of production to the sum of mortality.

Analyses of variance indicated no evidence of a production method $\times$ transplant date interaction for the three indices of production and mortality (RPM, RP, and RM; $P=0.416,0.749$, and 0.369 , respectively). Yet, when a priori contrasts were conducted, a pattern appeared in which the non-transplanted field treatment had the lowest values or least activity (except in RM), and the non-transplanted PIP treatment had the greatest values or most activity (Table 2). The differences among the values of the non-transplanted treatments relative to the transplanted treatments and each other reflect the relatively sparse root production by trees in the non-transplanted field treatment as well as the high root production of trees in the nontransplanted PIP treatment. The greater activity of the transplanted 
Table 1. Mean standing root length density and total annual root production and mortality of balled-and-burlapped (B\&B) and pot-in-pot (PIP) sugar maple transplanted in Nov. and Dec. 2000 and Mar., Apr., and July $2001(\mathrm{n}=4)$.

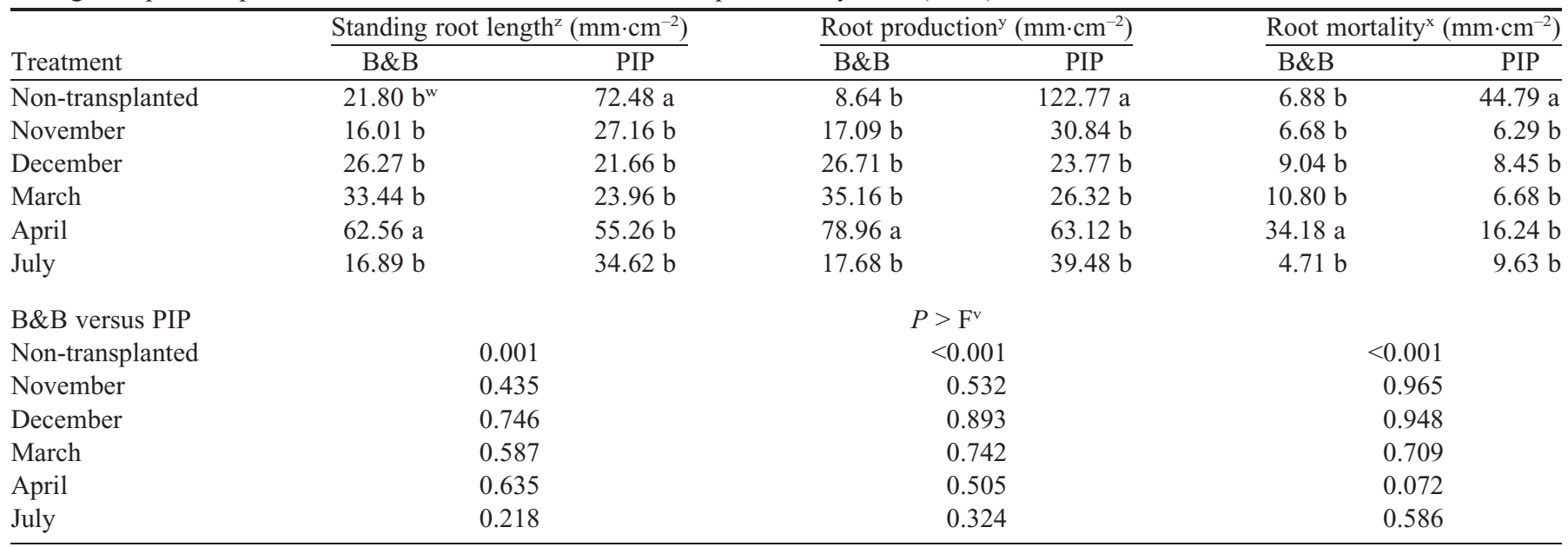

${ }^{\mathrm{z}}$ Mean of the four largest measurements from the first growing season.

${ }^{y}$ Sum of all new root lengths during the first year after transplant.

${ }^{x}$ Sum of all dead root lengths during the first year after transplant.

${ }^{w}$ Letters within columns indicate significance by a priori linear contrasts at $\alpha=0.05$.

vProbability values from a priori linear contrasts.

trees relative to the non-transplanted field trees likely represents the stimulation of anomalous root growth resulting from transplanting (Cripps, 1970; Watson and Himelick, 1982).

Estimates for the RP index of activity of the transplanted treatments in this study ranged between 1.02 and 1.25 per year (Table 2), which were larger than 0.79 to 0.83 range of values reported by Hendrick and Pregitzer (1993a) in a sugar mapledominated forest. The difference may reflect heightened root regeneration activities (i.e., increased production and/or lower relative mean standing root lengths) that are commonly seen in newly transplanted trees. In following with this argument, the RP index for the non-transplanted field treatment $(0.44$ per year) was much lower than in the B\&B transplants. The high RP value of 1.74 for the non-transplanted PIP likely reflected the influence of constraints on soil volume for roots to occupy.

The mortality-based RM index for the transplanted treatments and non-transplanted field treatment ranged between 0.26 and 0.56 per year, values that are very similar to those reported by Burton et al. (2000) for a sugar maple-dominated forest $(0.20$ to 0.52 per year). However, RM for the non-transplanted PIP treatments was very high (1.33 per year), again possibly reflecting the influence of the constrained soil volume of the pot.

P:M were greater than 1.0 in all transplanted treatments, and the lowest ratios occurred in non-transplanted trees $(0.90$ and 1.33 for field and PIP treatments, respectively). This was expected because newly transplanted trees must increase the size of root systems to supply demands made by the crown. As seen in the other indices, no production method $\times$ transplant date interaction was detected $(P=0.942)$ when activity was measured as a ratio of annual P:M. For this index of activity, contrast analysis (Table 2) also revealed no apparent interaction. November treatments had the highest P:M ratios (5.61 and 6.85 for B\&B and PIP treatments, respectively).

\section{Conclusions}

Similar to our study, Wiseman and Wells (2009) reported that root mortality was evident within the first month of new root observation and that production was very low and mortality generally high in the dormant winter/early spring season. Root mortality has mostly been assumed to be a minimal factor in the belowground dynamics of transplanted trees, especially for the first several weeks or months after root systems begin to regenerate. However, in view of our data (and those of Wiseman and Wells), this assumption can be incorrect. Data from this study indicate that root mortality can be a significant factor in the early dynamics of post-transplant root system regeneration.

Although we predicted that root production would dominate the dynamics of first-season belowground activity, we did not expect root mortality to be so substantial during the winter after the first post-transplant growing season. Root production was limited to the growing season when leaves were present and the photosynthetic machinery was in place. Root mortality, however, occurred year-round and reached a maximum in winter for the transplanted trees and late spring for the non-transplanted trees. The observed wintertime root mortality in transplanted trees may provide support for Watson's theory regarding "temporary" roots in transplanted trees (see earlier discussion). Substantial root mortality before periods of root production in all treatments except the non-transplanted field trees may also indicate competition for resources and the subsequent reallocation of carbon within the transplants. As well, early spring root production occurred later in the transplanted treatments relative to the non-transplanted field treatment, suggesting that transplanted trees may lack the carbon resources to support early spring root production.

Our prediction that fall- and early spring-transplanted trees would have a greater advantage in terms of root production, especially over summer-transplanted trees, did not appear to be true. Interestingly, the July transplants produced similar root lengths by the end of the first summer. As previously mentioned, the July transplants were irrigated so they likely did not face the same challenges as non-irrigated trees.

Non-transplanted trees in the PIPR exhibited production and mortality dynamics that were atypical of sugar maples in forest settings or trees grown in a nursery bed. The dynamics of the 
Table 2. Four indices of root production and mortality relative to standing root length [relative production and mortality (RPM), relative production (RP), relative mortality ( $\mathrm{RM})$, production/ mortality ratio $(\mathrm{P}: \mathrm{M})]$ of balled-and-burlapped $(\mathrm{B} \& \mathrm{~B})$ and pot-inpot (PIP) sugar maple transplanted in Nov. and Dec. 2000 and Mar., Apr., and July $2001(\mathrm{n}=4)$.

\begin{tabular}{|c|c|c|c|c|}
\hline Treatment & $\mathrm{RPM}^{\mathrm{z}}$ & $\mathrm{RP}^{\mathrm{y}}$ & $\mathrm{RM}^{\mathrm{x}}$ & $\mathrm{P}: \mathrm{M}^{\mathrm{w}}$ \\
\hline \multicolumn{5}{|l|}{$\mathrm{B} \& \mathrm{~B}$} \\
\hline Non-transplanted & $0.95 b^{v}$ & $0.44 \mathrm{~b}$ & $0.51 \mathrm{a}$ & $0.90 \mathrm{~b}$ \\
\hline November & $1.65 \mathrm{a}$ & $1.09 \mathrm{a}$ & $0.56 \mathrm{a}$ & $5.61 \mathrm{a}$ \\
\hline December & $1.35 \mathrm{a}$ & $1.02 \mathrm{a}$ & $0.34 \mathrm{a}$ & $3.09 \mathrm{at}$ \\
\hline March & $1.42 \mathrm{a}$ & $1.11 \mathrm{a}$ & $0.31 \mathrm{a}$ & $3.37 \mathrm{at}$ \\
\hline April & $1.77 \mathrm{a}$ & $1.25 \mathrm{a}$ & $0.53 \mathrm{a}$ & $2.40 \mathrm{at}$ \\
\hline July & $1.33 \mathrm{~b}$ & $1.03 \mathrm{a}$ & $0.30 \mathrm{a}$ & $5.13 \mathrm{ab}$ \\
\hline \multicolumn{5}{|l|}{ PIP } \\
\hline Non-transplanted & $3.07 \mathrm{a}$ & $1.74 \mathrm{a}$ & $1.33 \mathrm{a}$ & $1.33 \mathrm{~b}$ \\
\hline November & $1.42 \mathrm{~b}$ & $1.15 \mathrm{~b}$ & $0.27 \mathrm{~b}$ & $6.85 \mathrm{a}$ \\
\hline December & $1.56 \mathrm{~b}$ & $1.11 \mathrm{~b}$ & $0.45 \mathrm{~b}$ & $2.65 \mathrm{a}$ \\
\hline March & $1.33 \mathrm{~b}$ & $1.07 \mathrm{~b}$ & $0.26 \mathrm{~b}$ & $4.22 \mathrm{a}$ \\
\hline April & $1.46 \mathrm{~b}$ & $1.15 \mathrm{~b}$ & $0.31 \mathrm{~b}$ & $4.32 \mathrm{a}$ \\
\hline July & $1.44 \mathrm{~b}$ & $1.15 \mathrm{~b}$ & $0.29 \mathrm{~b}$ & $4.77 \mathrm{a}$ \\
\hline B\&B versus PIP & \multicolumn{4}{|c|}{$P>\mathrm{F}^{\mathrm{u}}$} \\
\hline Non-transplanted & $<0.001$ & $<0.001$ & $<0.001$ & 0.849 \\
\hline November & 0.282 & 0.628 & 0.065 & 0.589 \\
\hline December & 0.339 & 0.432 & 0.473 & 0.850 \\
\hline March & 0.741 & 0.798 & 0.795 & 0.763 \\
\hline April & 0.181 & 0.485 & 0.187 & 0.441 \\
\hline July & 0.628 & 0.349 & 0.947 & 0.878 \\
\hline
\end{tabular}

${ }^{\mathrm{z}} \mathrm{RPM}=(\mathrm{N}+\mathrm{D}) / \mathrm{SC}$ in which $\mathrm{N}=$ total annual root production calculated as sum of all new root lengths, $\mathrm{D}=$ total annual root mortality calculated as the sum of all dead root lengths, and $\mathrm{SC}=$ mean standing root length calculated as the mean of the four largest measurements.

${ }^{y} \mathrm{RP}=\mathrm{N} / \mathrm{SC}$.

${ }^{x} \mathrm{RM}=\mathrm{D} / \mathrm{SC}$.

wP:M = N/D.

'Letters within columns indicate significance by a priori linear contrasts at $\alpha=0.05$.

uprobability values from a priori linear contrasts.

non-transplanted field trees were most similar to reported dynamics of sugar maples in forest settings. Consequently, the results of this study indicate that transplanting and the PIP production system do disrupt typical patterns of root production and mortality. The highly dynamic nature of root systems of trees in the PIP production system may have consequences that affect nutrition within the PIP system and may be of interest to persons working with containerized trees and interested in carbon and nutrient cycling in the PIP production system.

\section{Literature Cited}

Amthor, J.S. 1984. The role of maintenance respiration in plant growth. Plant Cell Environ. 7:561-569.

Bevington, K.B. and W.S. Castle. 1985. Annual root growth pattern of young citrus trees in relation to shoot growth, soil temperature, and soil water content. J. Amer. Soc. Hort. Sci. 110:840-845.

Bloom, A.J., F.S.I. Chapin, and H. Mooney. 1985. Resource limitation in plants-An economic analogy. Annu. Rev. Ecol. Syst. 16:363-392. Bloomfield, J., K. Vogt, and P.M. Wargo. 1996. Tree root turnover and senescence, p. 363-381. In: Y. Waisel, A. Eshel, and U. Kafkafi (eds.). Plant roots: The hidden half. Marcel Dekker, New York, NY.
Burton, A.J., K.S. Pregitzer, and R.L. Hendrick. 2000. Relationships between fine root dynamics and nitrogen availability in Michigan northern hardwood forests. Oecologia 125:389-399.

Cripps, J.E.L. 1970. A seasonal pattern of apple root growth in Western Australia. J. Hort. Sci. 45:153-161.

Deans, J.D. and E.D. Ford. 1986. Seasonal patterns of radial root growth and starch dynamics in plantation-grown sitka spruce trees of different ages. Tree Physiol. 1:241-251.

Dickson, R.E. 1991. Episodic growth and carbon physiology in northern red oak, p. 117-124. In: S.B. Laursen and J.F. DeBoe (eds.). The oak resource in the upper Midwest: Implications for management. Univ. Minnesota, St. Paul, MN.

Eissenstat, D.M. and R.D. Yanai. 1997. The ecology of root lifespan. Adv. Ecol. Res 27:1-60.

Espeleta, J.F. and L.A. Donovan. 2002. Fine root demography and morphology in response to soil resources availability among xeric and mesic sandhill tree species. Funct. Ecol. 16:113-121.

Gilman, E.F. 1988. Tree root spread in relation to branch dripline and harvestable root ball. HortScience 23:351-353.

Gilman, E.F. and R.C. Beeson, Jr. 1996a. Nursery production method affects root growth. J. Environ. Hort. 14:88-91.

Gilman, E.F. and R.C. Beeson, Jr. 1996b. Production method affects tree establishment in the landscape. J. Environ. Hort. 14:81-87.

Harris, J.R. and J. Fanelli. 1999. Root and shoot growth periodicity of pot-in-pot red and sugar maple. J. Environ. Hort. 17:80-83.

Harris, J.R. and E.F. Gilman. 1993. Production method affects growth and post-transplant establishment of 'East Palatka' holly. J. Amer. Soc. Hort. Sci. 118:194-200.

Hendrick, R.L. and K.S. Pregitzer. 1992. The demography of fine roots in a northern hardwood forest. Ecology 73:1094-1104.

Hendrick, R.L. and K.S. Pregitzer. 1993a. The dynamics of fine root length, biomass, and nitrogen content in two northern hardwood ecosystems. Can. J. For. Res. 23:2507-2520.

Hendrick, R.L. and K.S. Pregitzer. 1993b. Patterns of fine root mortality in two sugar maple forests. Nature 361:59-61.

Hobbie, E.A., D.T. Tingey, P.T. Rygiewicz, M.G. Johnson, and D.M. Olszyk. 2002. Contributions of current year photosynthate to fine roots estimated using a ${ }^{13} \mathrm{C}$-depleted $\mathrm{CO}_{2}$ source. Plant Soil 247:233242.

Hutchings, M.J. 1988. Differential foraging for resources and structural plasticity in plants. Trends Ecol. Evol. 3:200-204.

Jones, R.H., R.J. Mitchell, G.N. Stevens, and S.D. Pecot. 2003. Controls of fine root dynamics across a gradient of gap sizes in a pine woodland. Oecologia 134:132-143.

Kolesnikov, V. 1971. The root system of fruit plants. Izdatelstvo mir, Moscow, Russia.

Kozlowski, T.T. and S.G. Pallardy. 1997. Physiology of woody plants. Academic Press, San Diego, CA.

Larson, M.M. 1984. Seasonal planting, root regeneration and water deficits of austrian pine and arborvitae. J. Environ. Hort. 2:33-38.

Lathrop, J.K. and R.A. Mecklenburg. 1971. Root regeneration and root dormancy in Taxus spp. J. Amer. Soc. Hort. Sci. 96:111-114.

Lawrence, W.T. and W.C. Oechel. 1983. Effects of soil temperature on the carbon exchange of taiga seedlings. I. Root respiration [Alnus crispa, Populus balsamifera, Populus tremuloides, Betula papyrifera, Alaska]. Can. J. For. Res. 13:840-849.

Marsh, B.A.B. 1971. Measurement of length in random arrangements of lines. J. Appl. Ecol. 8:265-267.

Marshall, J.D. and R.H. Waring. 1985. Predicting fine root production and turnover by monitoring root starch and soil temperature. Can. J. For. Res. 15:791-800.

Merritt, C. 1968. Effect of environment and heredity on the root growth pattern of red pine. Ecology 49:34-40.

Morrow, R.R. 1950. Periodicity and growth of sugar maple surface layer roots. J. For. 48:875-881.

Nambiar, E.K.S., G.D. Bowen, and R. Sands. 1979. Root regeneration and plant water status of Pinus radiata $\mathrm{D}$. Don seedlings transplanted to different soil temperatures. J. Expt. Bot. 30:1119-1131. 
Newman, E.I. 1966. A method of estimating the total length of root in a sample. J. Appl. Ecol. 3:139-145.

Pregitzer, K.S., R.L. Hendrick, and R. Fogel. 1993. The demography of fine roots in response to patches of water and nitrogen. New Phytol. 125:575-580.

Psarras, G., I.A. Merwin, A.N. Lakso, and J.A. Ray. 2000. Root growth phenology, root longevity, and rhizosphere respiration of field growth 'Mutsu' apple trees on 'Malling 9' rootstock. J. Amer. Soc. Hort. Sci. 125:596-602.

Richardson-Calfee, L.E., J.R. Harris, and J.K. Fanelli. 2007. Posttransplant root and shoot growth periodicity of sugar maple. J. Amer. Soc. Hort. Sci. 132:147-157.

Richardson-Calfee, L.E., J.R. Harris, and J.K. Fanelli. 2008. Root and shoot growth responses of balled-and-burplapped and pot-in-pot sugar maple to transplanting at five phenological stages. J. Environ. Hort. 26:171-176.

Santantonio, D. and J.C. Grace. 1987. Estimating fine-root production and turnover from biomass and decomposition data: A compartmentflow model. Can. J. For. Res. 17:900-908.

Taylor, J.S. and E.B. Dumbroff. 1975. Bud, root, and growth-regulator activity in Acer saccharum during the dormant season. Can. J. Bot. 53:321-331.

Tennant, D. 1975. A test of a modified line intersect method of estimating root length. J. Ecol. 63:995-1001.
Tierney, G.L. and T.J. Fahey. 2002. Fine root turnover in a northern hardwood forest: A direct comparison of the radiocarbon and minirhizotron methods. Can. J. For. Res. 32:1692-1697.

Vogt, K.A., R.L. Edmonds, and C.C. Grier. 1981. Seasonal changes in biomass and vertical distribution of mycorrhizal and fibrous-textured conifer fine roots in 23- and 180-year-old subalpine Abies amabilis stands. Can. J. For. Res. 11:223-229.

Wang, Z., W.H. Burch, P. Mou, R.H. Jones, and R.J. Mitchell. 1995. Accuracy of visible and ultraviolet light for estimating live root proportions with minirhizotrons. Ecology 76:2330-2334.

Watson, G.W. 1986. Cultural practices can influence root development for better transplanting success. J. Environ. Hort. 4:32-34.

Watson, G.W. 1987. The relationship of root growth and tree vigour following transplanting. J. Arboriculture 11:97-104.

Watson, G.W. and E.B. Himelick. 1982. Seasonal variation in root regeneration of transplanted trees. J. Arboriculture 8:305310 .

Watson, G.W. and E.B. Himelick. 1983. Root regeneration of shade trees following transplanting. J. Environ. Hort. 1:52-54.

Watson, G.W. and T.D. Sydnor. 1987. The effect of root pruning on the root system of nursery trees. J. Arboriculture 13:126-130.

Wiseman, P.E. and C.E. Wells. 2009. Arbuscular mycorrhizal innoculation affects root development of Acer and Magnolia species. J. Environ. Hort. 27:70-79. 